\title{
Application and Innovation of Architectural Decoration Materials in Modern Interior Design
}

\author{
Qi Li \\ Chongqing Vocational Institute of Engineering \\ School of art and design \\ (Chongqing, China 402260)
}

Keywords: Building decoration materials; Modern; Interior design; Application; Innovation

\begin{abstract}
The use of building decoration materials in the interior design are discussed, expounds the concrete application mode of stone and wood, glass fiber, fabric and ceramic materials in the interior design, and it puts forward innovative ways of building decoration materials in the interior design, in order to provide some advice on interior decoration for people.

With the continuous improvement of people's living standards, the interior design requirements are getting higher and higher, and there are more pursuit of comfort, beauty and economy. The traditional interior decoration materials can not fully meet the needs of people, and people's eyes gradually transferred to the building decoration materials, to explore potential innovative use of ordinary materials and innovate the use of new materials to meet the diversified and personalized needs of people are important.

Building decoration materials are also known as building finishes referring to the design of the surface of the building, decorative and beautify the environment to play a role in the material. These materials are combination of process, shape and aesthetics, and they are important parts of the building decoration project. Looking at the composition, properties of building decoration materials are rich in texture, color diversity, visual and emotional effects with different effects, with special beauty in interior design, designers should select and use materials according to the specific design requirements.
\end{abstract}

\section{Application of Architectural Decoration Materials in Modern Interior Design}

Application of stone decorative materials in interior design. As one of the most ancient building materials, stone materials are widely used in interior design, with continuous innovation, all kinds of stone material to enrich people's life, and the most extensive stone materials are marble and granite.

Marble is a metamorphic rock with strong compression resistance, soft texture, moderate hardness, easy processing and forming, and it is widely used in interior decoration. The marble is processed into a plate, which is polished to give a unique pattern and color. Marble used in bars, cabinets, tables and window sill, the condition of the tenants can also be decorated into marble ground and marble wall which can greatly improve the interior design level. Granite is an acidic rock with high $\mathrm{SiO} 2$. With its high weathering resistance, high hardness and high wear resistance, the colors include red, pink, gray and red, red brown and grey blue, after polished, it shows a beautiful speckled pattern in recent years to get more and more people of all ages. In the interior design, more processed into plate, and after polished it is used in the outdoor balcony, courtyard, dining room floor and window sill.

It is worth noting that the mirror surface of the stone water will slide the bathroom and toilet should be avoided; light colored stone is susceptible to pollution, pollution of the backward to the timely processing of juice splashing; some granite radiation can cause certain harm to human body, which should be carefully test before use.

Application of wooden architectural decorative materials in interior design. Woody materials have beautiful texture appearance, and they can be used in interior decoration design to give elegant, warm, gentle feelings, and with its unique structure, delicate texture and rich natural color, it can give a person with a sense of return to nature that is widely used in indoor decoration. 
Woody materials is the most ideal decoration materials and it can adjust the room temperature and humidity giving people comfortable environment, in the decoration, it has wood and wood-based panels form that is used in interior doors, furniture and floor, especially the bookshelf and desk as the use of wood material to create a heavy and peaceful atmosphere. In recent years, classical Chinese style decoration is more and more sought after by people. Wooden materials are used more and more widely, and most of them are favored by solid wood.

But wood material is easy to damp, deformation, and the shortcomings are susceptible to moth eaten and corrosion resistant, in the early installation, it must be good handling measures.

Application of glass decorative materials in interior design. Glass is a commonly used decorative material having a certain decorative, but it also has a strong practical, with elegant, fresh, crystal clear, clean and mild features, which is widely used in interior decoration. At present, the glass is not pure as lighting materials, laser glass and resplendent with variegated coloration for the living room ceiling, under the irradiation of light, changing colors of the pattern, it greatly enriched the light effect of space.

Glass mosaic can be combined into television background wall, in indoor important wall finishes, installing a painted glass or spray carved glass pendant can improve the indoor grade. Do partition, rack using sandblasting glass or carved glass, then a part of the TV wall can be directly used piece of glass, and light lanterns can achieve the very good effect that can also create a space like, or be divided into non interpenetration, like every other non isolation and continued space. In the main bedroom and living room, glass partition is widely used.

But the safety of the glass is a problem that can not be ignored, using explosion-proof glass or safety glass in the key parts can avoid harm to the human body.

Application of fiber decorative materials in interior design. Fiber fabric material has rich colors and sound characteristics of soft texture and rich elasticity, and this kind of fabric in the decoration can contrast the indoor atmosphere, enhance the artistic personality with the effect of icing on the cake of modern interior decoration.

In the decoration, fabric materials are widely used in bed, sofa, mask, carpet, foot pad and so on. To reduce noise, creating a comfortable environment supplys more and more soft decoration, and the soft decoration is also officially widely used fabric material.

Because of its loose, porous structure, suitable temperature and microbial growth, fiber fabric is easy to breed bacteria, and it should be cleaned regularly during usage.

Application of ceramic architectural decoration materials in interior design. Ceramic is the most widely used building decoration material, and it is a unique traditional art of our country. The most common is glazed tiles with beautiful, wear-resistant, non absorbent, washable and so on.

At present, glazed tile is the most widely used in indoor floor, bathroom overall, kitchen walls and so on. At the same time, some high-grade tiles have also been developed and applied to high-end residential areas.

\section{Innovation of Architectural Decoration Materials in Modern Interior Design}

With the continuous improvement of people's living standards, changing the concept of traditional materials and decoration methods have gradually emerged, in order to create a more comfortable living environment, people's focus gradually shifted to the innovation of traditional materials and design:

Exploring potential for use, innovating ways of combining. In interior design, various decoration materials have unique properties and unique decorative features, in the design work in the past, due to material type and the limitation of people of different ideas, and then the design process often adhere to a lack of innovation. In recent years, the new building decoration materials emerge in an endless stream with a wide variety of new design, decoration process continues to progress for interior design innovation providing greater possibilities.

In interior design, designers should fully understand the properties of materials, digging into the potential use of materials, while not rigidly adhere to the traditional form, and searching for new ways of combining materials and different materials. The specific approach is: to design by using a 
combination of old material color and pattern, the old materials in new ways with new vitality; with the development of society, building decoration materials that continue to emerge, and the interior designers should understand and grasp the characteristics of the new materials which should be good at using the new building decoration materials in the design in the process, according to the decoration scheme provided by owner, it should hold the essence of interior design that is reasonable for collocation of various materials, and creativity on the basis of this, using a variety of design and decoration method can make up the defects of a single material to obtain the good decoration effect.

Using ordinary materials, innovating decorative effect. In interior design, it can make a clever use of ordinary materials with innovative decorative effect. The gist of interior design is to obtain a comfortable living environment, the innovation is not a single and whimsical innovation, but a basic understanding of the material properties and the key points of interior design on the clever use of ordinary materials based on and get a multiplier effect. In the process of innovative application of architectural decoration materials, the different decorative materials and different visual effects can be displayed in different ways.

The designer should understand and grasp the characteristics and style of decoration materials, constructing process and the combination of common materials through innovative ways, which can show the overall design intent, and keeping out of the ordinary form. For example, when designing suspended ceiling in wet space, waterproof paint can be sprayed outside to ensure the continuity and integrity of the design. In the design process, designers should pay attention to the design of the whole injection of emotion in order to create a fresh sense of shape. For example, when designing a bookshelf, it can consider the use of wooden structure, and select the right plate or the plate as a coordinated color according to the overall design style to get a harmonious style.

Combining building decoration materials, light and color to obtain more intense aesthetic feeling. The innovative use of building decoration materials is not an isolated single effect which can through the combination of material and light, color and other elements, and the integration of environment itself and the environment re-shape to get out of the ordinary and colorful visual effects. The combination of building materials with light and color can not only meet the practicability, but also better reflect the overall aesthetic and cultural connotations in the use of building decoration materials.

Building decoration materials have different texture, luster itself and different characteristics of different thickness, different kinds of materials are absolutely different: glass has a bright color, and high transparency characteristics of the decoration process can show strong expressive and lively performance.

But with the combination of light and color elements that are not stereotyped, but also have different kinds of materials with different light and color together through the overall harmony, texture and the effect of different. In the use of color, it should pay attention to the design of space in the overall tone of unity in seeking changes in unity. For example, a new type of liquid wallpaper is compared with the traditional wallpaper having better moisture resistance, aging resistance and aging resistance, and it also has its own different colors for selection in wallpaper selection according to the indoor light.

\section{Conclusion}

Building decoration materials have many types, to increase the technology exchange and learning, designers or construction personnel should enhance the material and knowledge ability, taking into account the characteristics of stone, wood and other materials, enhancing the use of traditional building materials ability while building decoration materials used in modern interior design. Through deeply exploring the potential of the use of materials combined with innovative materials; the use of ordinary materials with innovative decorative effect; and building decoration materials with light and color combination through innovative use of more intense beauty and other ways to complete the building decoration materials in the interior design in order to obtain a better effect and rich people's life. 


\section{Reference}

[1]Bo Wang, Chaohui Liu, Zhengxiang Zhao.Preliminary discussion on construction planning of decorative materials and structures laboratory[J].Journal of North China Institute of Science and Technology.2012(03).

[2]Decan Hu.Application of ecological building materials in interior decoration[J].Journal of Ezhou University.2012(05).

[3]Xia Li.Application of decorative materials in residential space[J].Modern decoration (Theory).2012(09).

[4]Chao Yan.Analysis on expressive force of decorative materials in interior design[J].China Science and Technology Expo, 2011(03). 